\title{
Impact of a Decision Aid on Surrogate Decision-makers' Perceptions of Feeding Options for Patients with Dementia
}

\author{
E. Amanda Snyder ${ }^{1}$, Anthony J. Caprio, MD ${ }^{1}$, Kathryn Wessell ${ }^{2}$, Feng Chang Lin, PhD $^{3}$, and \\ Laura C. Hanson, MD, MPH ${ }^{1,2}$ \\ ${ }^{1}$ Division of Geriatric Medicine and Center for Aging and Health, School of Medicine, University of \\ North Carolina, Chapel Hill, NC \\ ${ }^{2}$ Cecil G. Sheps Center for Health Services Research, University of North Carolina, Chapel Hill, \\ $\mathrm{NC}$ \\ ${ }^{3}$ Department of Biostatistics, School of Public Health, University of North Carolina, Chapel Hill, \\ $\mathrm{NC}$
}

\begin{abstract}
Objective-In advanced dementia, feeding problems are nearly universal, and families face difficult decisions about feeding options. Initial interviews for a randomized trial were used to describe surrogates' perceptions feeding options, and to determine if a decision aid on feeding options in advanced dementia would improve knowledge, reduce expectation of benefit from tube feeding, and reduce conflict over treatment choices for persons with advanced dementia.
\end{abstract}

Design-Semi-structured interview with pre-post study design for surrogates in the intervention group.

Setting-Twenty-four skilled nursing facilities across North Carolina participating in a cluster randomized trial.

Participants-Two hundred fifty-five surrogate decision-makers for nursing home residents with advanced dementia and feeding problems, in control $(n=129)$ and intervention $(n=126)$ groups.

Intervention-For intervention surrogates only, an audiovisual-print decision aid provided information on dementia, feeding problems in dementia, advantages and disadvantages of feeding tubes or assisted oral feeding options and the role of surrogates in making these decisions.

Measurements-The interview included open-ended items asking surrogates to report advantages and disadvantages of tube feeding and assisted oral feeding. Knowledge of feeding options was measured with 19 true-false items, and items measuring expectation of benefit from tube feeding. Surrogates reported which of these two feeding options they preferred for the person with dementia, and how confident they were in this choice; their level of conflict about the choice was measured using the Decisional Conflict Scale.

(C) 2012 American Medical Directors Association. Published by Elsevier Inc. All rights reserved.

ClinicalTrials.gov registration: University of North Carolina-Chapel Hill, NCT01113749. http://clinicaltrials.gov/ct2/show/ NCT01113749

CONFLICT OF INTEREST: Authors have no conflicts of interest related to this research.

Publisher's Disclaimer: This is a PDF file of an unedited manuscript that has been accepted for publication. As a service to our customers we are providing this early version of the manuscript. The manuscript will undergo copyediting, typesetting, and review of the resulting proof before it is published in its final citable form. Please note that during the production process errors may be discovered which could affect the content, and all legal disclaimers that apply to the journal pertain. 
Results-Prior to the decision aid, surrogates described advantages and disadvantages of assisted oral feeding and tube feeding in practical, ethical and medical terms. After review of the decision aid, intervention surrogates had improved knowledge scores (15.5 vs. 16.8; $\mathrm{p}<0.001)$, decreased expectation of benefits from tube feeding ( 2.73 vs. $2.32 ; p=0.001)$ and reduced decisional conflict (2.24 vs. 1.91, $\mathrm{p}<0.001)$. Surrogates preferred assisted oral feeding initially, and reported more certainty about this choice after the decision aid.

Conclusion-A structured decision aid can be used to improve decision-making about feeding options in dementia care.

\section{INTRODUCTION}

Dementia is a progressive incurable illness causing functional decline and death years after diagnosis. ${ }^{1,2,3}$ Advanced dementia is characterized by dependence for eating, and $86 \%$ of persons with advanced dementia develop feeding problems. ${ }^{4,5}$ Faced with weight loss, dehydration or aspiration, family members struggle with the emotionally difficult decision to continue assisted oral feeding or consider use of a feeding tube.

Surrogate decision making is a common practice in the nursing home environment; $50 \%$ of residents have dementia and $67 \%$ of dementia-related deaths occur in this setting. ${ }^{6}$ Family surrogate decision-makers often feel unprepared and unsupported when making treatment choices for persons with dementia. ${ }^{7,8}$ Consent discussions about feeding tubes routinely focus on the risks associated with the procedure as opposed to long term outcomes and alternatives. ${ }^{9,10}$ Furthermore, research indicates families and physicians may overestimate the benefits of tube feeding. ${ }^{11,12}$ Many patients with advanced dementia receive a feeding tube despite data demonstrating no improvement in survival, aspiration risks or wound healing. ${ }^{13,14,15,16,17,18}$

Decision aids provide structured information and are effective to increase knowledge and reduce decisional conflict. ${ }^{19,20,21}$ Despite the need to make major medical treatment choices for patients with cognitive deficits, decision aids are rarely designed for surrogates. We used interviews before and after review of a decision aid to meet these aims: (1) to describe surrogates' baseline perceptions of the advantages and disadvantages of feeding options in dementia and (2) to determine if a decision aid on feeding options in advanced dementia alters surrogate decision-makers' knowledge, expectation of benefit from tube feeding, decisional conflict, and preferred feeding approach in advanced dementia.

\section{METHODS}

\section{Study Design}

Surrogate decision-makers for nursing home residents with advanced dementia participated in in-person interviews, with data obtained before and after review of an audiovisual decision aid. These were baseline interviews for a large randomized controlled trial, with planned longitudinal follow-up of the effects of the decision aid on the quality of decision making. ${ }^{22,23}$ The decision aid, based on an early prototype by Mitchell, provided information about surrogate decision-making, dementia and feeding problems, and the advantages and disadvantages of feeding tubes or assisted oral feeding options. ${ }^{24,25}$ Information was presented at a sixth grade reading level and piloted for acceptability and cultural sensitivity. Research assistants were present during the viewing and trained to answer questions for clarification only; requests for additional information were directed to the treating clinician. Control subjects responded to interview items without the decision aid. 


\section{Research Setting and Subjects}

The study was conducted in 24 skilled nursing facilities in North Carolina. Sites were randomized in pairs matched for business model (for-profit vs. not-for-profit), size and proportion of African American residents. Subjects were surrogate decision-makers for residents with advanced dementia and feeding problems. Residents with advanced dementia had a chart diagnosis of dementia and severity staged as a 6-7 on the Global Deterioration Scale (GDS). ${ }^{4}$ Eligible residents had documented evidence of feeding problems defined as poor intake, dysphagia or weight loss in their medical record and/or Minimum Data Set (MDS). ${ }^{22,23}$ Subjects were enrolled between August 2007 and July 2009. Surrogates provided written informed consent for themselves and the resident with dementia. All research procedures were approved by the Institutional Review Board (IRB) of the University of North Carolina School of Medicine, and for individual sites by the IRBs of Alamance Regional Hospital and East Carolina University Brody School of Medicine.

\section{Data Collection and Measures}

Trained research assistants collected data during baseline in person interviews with surrogates. To meet the first aim, surrogates in intervention and control groups were prepared for open-ended questions with this introduction: "When residents with dementia have problems with eating and drinking, their families and physician may need to decide whether to continue food by mouth or to consider a feeding tube. Assistance with eating by mouth means having another person help with taking in food by mouth. This can include feeding by hand, changing foods to make them easier to eat, and encouraging a person to eat. For this study, we mean a feeding tube that goes through the skin into the stomach or intestine, so the person can receive a nutritious liquid. It is used to deliver food straight into the stomach without eating." Subjects were subsequently asked "In your opinion, what are 2 advantages of assistance with eating by mouth for people like [RESIDENT]?' Parallel items were used to ask about disadvantages associated with eating by mouth, and the advantages and disadvantages of tube feeding. Responses to these questions were written verbatim by the interviewer.

To meet the second aim, intervention surrogates' responses to structured measures of knowledge, expectation of benefits from tube feeding, and decisional conflict were compared before and after review of the decision aid. Knowledge was measured using 19 true/false items about dementia and feeding options, scored 0-19 for the number of correct responses. Knowledge of tube feeding outcomes was examined using the Expectation of Benefit Index. This index employs 11 Likert-scale items measuring the potential benefits of tube feeding, and was used in a prior study of decision-making. ${ }^{11}$ Scores range from 1-4, with lower scores indicating better knowledge. Decisional conflict was measured using the Decisional Conflict Scale. This scale consists of 16 items scored 1-5 with higher scores indicating greater conflict; it has good test-retest reliability and validity. ${ }^{26}$ Finally, intervention surrogates' preference for feeding was evaluated before and after exposure to the decision aid, and certainty of preference was rated on a visual analog scale from 0 (certain that assistance with eating by mouth is the right choice) to 10 (certain that tube feeding is the right choice.)

Surrogates also provided data on their age, gender, race, religion and relationship to resident, and the frequency of visits and communication with facility staff during the past month.

\section{Analysis}

To meet the first aim, investigators used inductive consensus coding to analyze surrogates' responses to open-ended questions about the advantages and disadvantages of each of the two major feeding options. Three investigators independently coded responses from the first 
thirty (30) subjects, then discussed and reached consensus on coding categories. Codes for advantages and disadvantages in the decision aid were included a priori; investigators proposed and discussed new codes for other responses. Using an iterative approach, the investigators independently coded data and codes were refined until all new data fit existing codes. Upon finalization of the code list, subsequent responses were coded by trained interviewers and confirmed by investigators. Coded responses for all surrogates - control and intervention surrogates prior to viewing the decision aid - were used to describe perceptions of the advantages and disadvantages of the two main feeding options.

To meet the second aim, intervention surrogates' responses were compared pre- and postdecision aid for the knowledge items, Expectation of Benefit Index, Decisional Conflict Scale, and the surrogates' preferred approach to feeding for the resident with dementia. Statistical analyses used either McNemar's test or paired t-test, respectively, for binary or continuous responses in pre-post comparison within the same subject. All of the analyses were adjusted by intraclass correlation for the nursing home sampling unit; $p$ values less than 0.05 were considered significant.

\section{RESULTS}

Of 425 eligible surrogates, 256 consented to participate (60\%). One intervention surrogate did not complete all items in the interview, leaving complete data for 126 intervention and 129 control surrogates.

\section{Subject Characteristics}

The average age of surrogates was 59 years; most were Caucasian and female (Table 1). Surrogates were usually the sons or daughters of the nursing home residents, and they reported regular visiting and communication with staff. These characteristics did not differ between groups at baseline.

\section{Surrogates' Perceptions of Advantages of Assistance with Eating by Mouth}

When surrogate decision-makers reported the main advantages of assistance with oral feeding in their own words, they most often described enjoyment of food and drink, health and nutrition, and effectiveness (Table 2). Responses related to enjoyment of food and drink category included surrogates' perception that assisted feeding made eating more pleasant, and it promoted emotional connections and memories associated with eating. For health and nutrition, surrogates discussed medical benefits from food variety and proper nutrition, as well as ease of monitoring the quantity of food taken. Responses indicating effectiveness included assisted feeding as a way to ensure the resident was physically able to eat, and endorsement for the importance of human encouragement in the feeding process. Personal assistance with eating ensured that a resident with dysphagia had the type of foods she can "eat properly with no chewing or swallowing problems" so she "does not eat too much and choke."

Although not as common, some surrogates also cited dignity as a major advantage of assisted oral feeding. These responses stressed the importance of eating by mouth in protecting personhood despite advanced dementia. Other less commonly cited advantages of assistance with eating by mouth included normalcy, showing caring, extra time with caregiver, and respecting patient wishes. Surrogates expressed the value of maintaining eating as a normal part of life. They described the increased contact and attention, and social interaction as advantages of assistance with eating. Some surrogates noted that caregivers providing hand feeding spent more time with the resident, resulting in an increased awareness of their needs. 


\section{Surrogates' Perceptions of Disadvantages of Assistance with Eating By Mouth}

Surrogates' most common responses for disadvantages of assistance with eating described an unpleasant experience, with concerns for loss of independence, choking, and uncertainty in amount of food or drink (Table 2). In the category of unpleasant experience, surrogates noted the resident may not like the food choices or may be overfed, or experience spilling and messiness associated with assisted oral feeding. Surrogates' concerns about the loss of independence reflected the idea that assisted feeding may build dependency and erode dignity. Under the category of choking, surrogates discussed the risks of aspiration and pneumonia as potential disadvantages. Finally, in responses indicating uncertainty in amount of food, surrogates mentioned the resident "may not get enough nutrition," or only "eat enough to subside hunger but not to maintain weight level." They noted residents" potential to forget to eat or drink as a disadvantage of assistance with eating. Less commonly cited disadvantages for assistance with eating by mouth included its greater time intensity, concerns about the quality of assistance, including improper handling of food or cold food, and general comments on its ineffectiveness.

\section{Surrogates' Perceptions of Advantages of Tube Feeding}

When asked to list advantages of tube feeding, surrogate decision-makers most commonly discussed complete nutrition, survival, and less time. Surrogates saw tube feeding as providing consistent nutrition and weight maintenance, due to complete nutrition. They reported prolonged survival as an advantage; responses focused on the feeding tube's ability to "keep person alive longer" and "ensure basic survival if [resident] cannot feed themselves." Tube feeding was perceived as demanding less time of caregivers, and a more efficient way to give nutrition. Tube feeding was also perceived as advantageous because of the ease of the feeding process, and the avoidance of staff and resident struggle. Other benefits included greater comfort for the patient and family, and the healing of bedsores. Among less common responses, surrogates perceived that tube feeding resulted in less choking and less concern for hunger and thirst, some specifically cited tube feeding as preventing starvation.

\section{Surrogates' Perceptions of Disadvantages of Tube Feeding}

For disadvantages associated with tube feeding, the most common responses from surrogate decision-makers were tube-related complications, concern for inappropriately prolonging life, less enjoyment or pleasure and against resident's prior wishes. When discussing tuberelated complications, surrogates cited the invasive nature, discomfort and increased risk associated with tube feeding. A commonly noted disadvantage of tube feeding was inappropriately prolonging life, described as prolonging "the inevitable" and "extending life when there is no quality." Surrogates cited their belief in the naturalness of dying and the inhumane nature of tube feeding as disadvantages. In the less enjoyment category, surrogates noted tube feeding caused a loss of "psychological pleasure of eating" and the "mental anguish - cannot eat by mouth and always thinking about food." Other responses in this category demonstrated concern for decreased quality of life and mobility as a result of being tube fed. Surrogates saw tube feeding as problematic when it was against prior wishes of the person with dementia, as a result of personal preference or religious beliefs. Finally, small numbers of surrogates noted other disadvantages, such as loss of normalcy, poor nutrition, loss of independence or dignity, less interaction or contact, risk of resident pulling tube out, limitations in sites of care, unchanged risk in aspiration and difficulty in discontinuing use once started. 


\section{Effect of the Decision Aid on Knowledge, Expectation of Benefit and Treatment Preferences}

Comparing answers before and after exposure to the decision aid, surrogates had significantly more correct answers to knowledge items. (Table 3) After the decision aid, they had decreased Expectation of Benefit index scores, consistent with less expectation of benefit from tube feeding ( 2.73 vs. $2.32 ; \mathrm{p}=0.001$ ). On individual items within this index, surrogates were less likely to expect tube feeding would improve pain (2.34 vs. 2.12 ; p $=0.047)$, problems with feeding ( 3.31 vs. $3.02 ; \mathrm{p}=0.005)$, quality of life (2.12 vs. $1.93 ; \mathrm{p}=$ 0.01 ) and survival ( 3.10 vs. $1.72 ; \mathrm{p}=0.000)$. They were also less likely to believe that tube feeding reduced the risk of pneumonia (2.87 vs. $2.04 ; \mathrm{p}=0.000)$, coughing episodes ( $2.97 \mathrm{vs.}$ $2.36 ; \mathrm{p}=0.001)$ and choking episodes (3.45 vs. $2.60 ; \mathrm{p}=0.000$ ).

Surrogates had lowered levels of overall decisional conflict following the decision aid (2.24 pre vs. 1.91 post, $\mathrm{p}<0.001$ ), and lower subscale scores for uncertainty and factors contributing to uncertainty. Nearly all surrogates were predisposed to choose assistance with oral feeding over tube feeding, and this preference did not change after the decision aid ( $96 \%$ vs. $98 \%$, p=NS). However, surrogates' rating of certainty about their choice of oral feeding improved significantly (1.35 vs. $1.05 ; \mathrm{p}=0.016)$.

\section{DISCUSSION}

In interviews with surrogate decision-makers for persons with advanced dementia, we found that an audiovisual decision aid improved informed decision-making about the choice between assisted feeding and tube feeding. Prior to the decision aid, surrogates' perceptions of feeding options were varied and included ethical and practical concerns as well as attention to medical outcomes. The decision aid improved knowledge, and made them less likely to expect prolonged survival, reduced aspiration, or improvements in pain or quality of life. However, nearly all surrogates were initially predisposed to prefer assisted feeding over tube feeding, and use of the decision aid reduced decisional conflict and strengthened certainty that assisted oral feeding was optimal. Though no surrogate data was collected after three months, residents were followed for up to 9 months or death with low rates of tube feeding in both intervention and control groups. The improvement in decisional conflict and knowledge gained from the decision aid could provide long-term benefit if the choice between assisted feeding and tube feeding is readdressed during a hospitalization or acute decline in health status.

Prior to the decision aid, surrogates were able to identify advantages and disadvantages of assisted feeding and tube feeding for persons with dementia, but their perceptions were not always consistent with medical evidence. They saw assistance with eating by mouth as enjoyable, healthy and effective, and a way to promote dignity and express caring for the person with dementia. However, some surrogates also expressed concerns that assisted feeding could be messy or ineffective, cause choking, and erode remaining independence. Greater attention to these aspects of assisted feeding may improve its acceptance by families.

Surrogates assumed that tube feeding would prolong survival, and considered this both an advantage and a disadvantage for persons with dementia. This apparent moral contradiction is likely a result of the ethical dilemmas surrounding the dying process when illness is prolonged and severely symptomatic. Tube feeding is often considered as a "life-sustaining treatment," and widely publicized cases of tube feeding in patients with coma or vegetative state reinforce this concept. Surrogates in this study lacked knowledge of the limited effectiveness of tube feeding in advanced dementia. These findings may be used to deepen clinicians' understanding of surrogates' preparation for decision-making, to promote 
information sharing on lack of medical benefits of tube feeding, and attention to positive attributes of oral feeding. The audiovisual decision aid is 20 minutes long and could easily be used to enhance and support communication and decision-making between surrogates and providers. ${ }^{25}$ As demonstrated in one quality improvement intervention by Monteleoni, tube feeding decisions for advanced dementia patients changes when surrogates are given greater opportunity for shared decision-making. ${ }^{27}$

Study results should be interpreted in the context of limitations. Cross-sectional interviews do not allow testing for effects of the decision aid on surrogate behaviors and treatment choices. Other factors may influence actual treatments, such as staffing efficiency, physician advice, or the impact of a future illness on feeding. Research sites were all in North Carolina, and geographic variation in the use of feeding tubes for dementia care may limit generalizability of the results. Optimal shared decision-making may require improved staffing and staff training in assisted feeding techniques, and attention to organizational, regional and cultural norms that encourage tube feeding as a default option. ${ }^{28,29}$

\section{CONCLUSION}

Surrogate perspectives on the advantages and disadvantages of assisted feeding and feeding tubes for persons with advanced dementia are varied and do not always correspond with medical evidence. Exposure to a structured decision aid significantly improved surrogate knowledge of feeding options, reduced decisional conflict and improved certainty that assisted oral feeding is optimal care. Surrogates are interested in and willing to incorporate information from the decision aid, and this approach can be used to improve the decisionmaking process for feeding options in dementia care.

\section{Acknowledgments}

Funding source: NIH-National Institute for Nursing Research R01 NR009826; NIH-National Institute on Aging T35AG038047.

The John B. Graham Student Research Society at The University of North Carolina, UNC Center for Aging and Heath, American Federation for Aging Research and Ellen Roberts, PhD, MPH for her support and guidance.

\section{References}

1. Herbert LI, Scherr PA, Bienia JL, Bennett DA, Evans DA. Alzheimer's disease in the US population: prevalence estimates using the 2000 census. Arch Neurol. 2003; 60:1119-22. [PubMed: 12925369]

2. Larson EB, Shadlen MF, Wang L, McCormick WC, Bowen JD, Teri L, et al. Survival after intial diagnosis of Alzheimer disease. Ann Intern Med. 2004; 140:501-509. [PubMed: 15068977]

3. Boustani M, Peterson CB, Hanson LC, Harris R, Lohr KN. Screening for dementia syndrome: a review of the evidence. Ann Intern Med. 2003; 138:927-937. [PubMed: 12779304]

4. Reisberg B, Ferris SH, De Leon MJ, Crook T. The global deterioration scale for assessment of primary degenerative dementia. Am J Psychiatry. 1982; 139:1136-39. [PubMed: 7114305]

5. Mitchell SL, Teno JM, Kiely DK, Shaffer ML, Jones RN, Prigerson HG, et al. The clinical course of advanced dementia. N Engl J Med. 2009; 361:1529-1538. [PubMed: 19828530]

6. Magaziner J, German P, Zimmerman S, Hebel JR, Burton L, Gruber-Baldini AL. The prevalence of dementia in a statewide sample of new nursing home admissions aged 65 and older: diagnosis by an expert panel. Gerontologist. 2000; 40:663-672. [PubMed: 11131083]

7. Maust DT, Blass DM, Black BS, et al. Treatment decisions regarding hospitalization and surgery for nursing home residents with advanced dementia: The Care AD Study. Int Psychogeriatr. 2008;

20:406-418. [PubMed: 17825116] 
8. Givens JL, Kiely DK, Carey K, Mitchell SL. Health care proxies of nursing home residents with advanced dementia: decisions they confront and their satisfaction with decision-making. $\mathrm{J}$ Am Geriatr. 2009; 57:1149-1155.

9. Brett AS, Rosenberg JC. The adequacy of informed consent for placement of gastrostomy tubes. Arch Intern Med. 2001; 161:745-748. [PubMed: 11231709]

10. Lewis CL, Hanson LC, Golin C, Garrett JM, Cox CE, Jackman A, et al. Surrogates' perceptions about feeding tube placement decisions. Patient Educ Couns. 2006; 61:246-52. [PubMed: 16503108]

11. Carey TS, Hanson LC, Garrett JM, et al. Expectations and outcomes of gastric feeding tubes. Am J Med. 2006; 119(6):527.e11-16. [PubMed: 16750971]

12. Hanson LC, Garrett JM, Lewis C, Phifer N, Jackman A, Carey TS. Physicians' expectations of benefit from tube feeding. J Palliat Med. 2008; 11:1130-1134. [PubMed: 18980454]

13. Sloane PD, Zimmerman S, Williams CS, Hanson LC. Dying with dementia in long-term care. Gerontologist. 2008; 48:741-751. [PubMed: 19139248]

14. Mitchell SL, Kiely DK, Lipsitz LA. The risk factors and impact on survival of feeding tubes in nursing home residents with advanced dementia. Arch Intern Med. 1997; 157:327-332. [PubMed: 9040301]

15. Meier DE, Aronheim JC, Morris J, Baskin-Lyons S, Morrison RS. High short-term mortality in hospitalized patients with advanced dementia: lack of benefit of tube feeding. Arch Intern Med. 2001; 161:594-599. [PubMed: 11252121]

16. Murphy LM, Lipman TO. Percutaneous endoscopic gastrostomy does not prolong survival in patients with dementia. Arch Intern Med. 2003; 163:1351-1353. [PubMed: 12796072]

17. Sampson, EL.; Candy, B.; Jones, L. Enteral tube feeding for older people with advanced dementia. http://www2.cochrane.org/reviews/en/ab007209.html. Published Jan, 2009, viewed May 20, 2009

18. Cai S, Gozalo PL, Mitchell SL, Kuo S, Bynum JP, Mor V, Teno JM. Do patients with advanced cognitive impairment admitted to hospitals with higher rates of feeding tube insertion have improved survival? J Pain Symptom Manage. 2012 e-pub ahead of print.

19. Bennett CL, Stacey D, Barry M, Col NF, Eden KB, et al. Decision aids for people facing health treatment or screening decisions. Cochrane Database Syst Rev. 2009 Jul 8.(3):CD001431. [PubMed: 19588325]

20. Whelan T, Levine M, Willan A, Gafni A, Sanders K, Mirsky D, et al. Effects of a decision aid on knowledge and treatment decision making for breast cancer surgery. JAMA. 2004; 292:235-441.

21. Barry MJ. Health decision aids to facilitate shared decision making in office practice. Ann Intern Med. 2002; 136:127-135. [PubMed: 11790064]

22. Hanson LC, Gilliam R, Lee TJ. Successful clinical trials research in nursing homes: The Improving Decision Making Study. Clin Trials. 2010; 7:735-43. [PubMed: 20729251]

23. Hanson LC, Carey T, Caprio A, Lee TJ, Ersek M, Garret J, Jackman A, Gilliam R, Wessell K, Mitchell S. A randomized trial of a decision aid for feeding options in advanced dementia. J Am Geriatr Soc. 2011; 59:2009-2016. [PubMed: 22091750]

24. Mitchell SL, Tetroe J, O'Conner AM. A decision aid for long-term tube feeding in cognitively impaired older persons. J Am Geriatr Soc. 2001; 49:313-316. [PubMed: 11300244]

25. Improving Decision Making decision aid, available on i Tunes U. UNC Chapel Hill; http:// itunes.apple.com/itunes-u/aging-disability-long-term/id431759148 viewed July 5, 2012

26. O’Connor AM. Validation of a Decisional Conflict Scale. Med Decis Making. 1995; 15:25-30. [PubMed: 7898294]

27. Monteleoni C, Clark E. Using rapid-cycle quality improvement methodology to reduce feeding tubes in patients with advanced dementia: before and after study. BMJ. 2004; 329:491-494. [PubMed: 15331474]

28. Hanson LC, Ersek M, Gilliam R, Carey T. Oral feeding options for people with dementia: a systematic review. J Am Geriatr Soc. 2011; 59:463-72. [PubMed: 21391936]

29. Mitchell SL, Teno JM, Roy J, et al. Clinical and organizational factors associated with feeding tube use among nursing home residents with advanced cognitive impairment. JAMA. 2003; 290:73-80. [PubMed: 12837714] 
TABLE 1

Surrogate Characteristics by Intervention Group

\begin{tabular}{|c|c|c|c|}
\hline Characteristic & Intervention $(n=127)$ & Control (n=129) & p value* \\
\hline Age & 59.3 & 58.7 & 0.89 \\
\hline \multicolumn{4}{|l|}{ Gender } \\
\hline Male & $32 \%$ & $42 \%$ & 0.09 \\
\hline Female & $68 \%$ & $58 \%$ & \\
\hline \multicolumn{4}{|l|}{ Race } \\
\hline White & $67 \%$ & $73 \%$ & 0.57 \\
\hline African American & $31 \%$ & $26 \%$ & \\
\hline American Indian & $2 \%$ & $2 \%$ & \\
\hline Other & $1 \%$ & $0 \%$ & \\
\hline Hispanic/Latino & $2.4 \%$ & $0 \%$ & -- \\
\hline \multicolumn{4}{|l|}{ Religion } \\
\hline Protestant & $75 \%$ & $68 \%$ & 0.40 \\
\hline Catholic & $4 \%$ & $6 \%$ & \\
\hline Jehovah's Witness & $3 \%$ & $2 \%$ & \\
\hline Jewish & $1 \%$ & $2 \%$ & \\
\hline No Religion & $7 \%$ & $5 \%$ & \\
\hline Other & $10 \%$ & $17 \%$ & \\
\hline \multicolumn{4}{|l|}{ How Religious } \\
\hline Very & $45 \%$ & $47 \%$ & 0.94 \\
\hline Moderately & $41 \%$ & $37 \%$ & \\
\hline Slightly & $10 \%$ & $13 \%$ & \\
\hline Not religious & $3 \%$ & $3 \%$ & \\
\hline Don’t Know & $0 \%$ & $1 \%$ & \\
\hline \multicolumn{4}{|l|}{ Relationship } \\
\hline Spouse & $7 \%$ & $9 \%$ & 0.62 \\
\hline Daughter & $48 \%$ & $43 \%$ & \\
\hline Son & $20 \%$ & $29 \%$ & \\
\hline Grandchildren & $5 \%$ & $4 \%$ & \\
\hline Nephews \& Nieces & $8 \%$ & $8 \%$ & \\
\hline Siblings & $7 \%$ & $4 \%$ & \\
\hline Other Family & $4 \%$ & $2 \%$ & \\
\hline Non-Family & $2 \%$ & $2 \%$ & \\
\hline Average \# of visits in last month & 12.3 & 12.3 & 0.996 \\
\hline Average \# of days they spoke with staff & 8.7 & 9.7 & 0.236 \\
\hline
\end{tabular}


TABLE 2

Surrogate Decision-makers' Perceptions of Feeding Options at Baseline $(\mathrm{n}=255)$

\begin{tabular}{|c|c|}
\hline 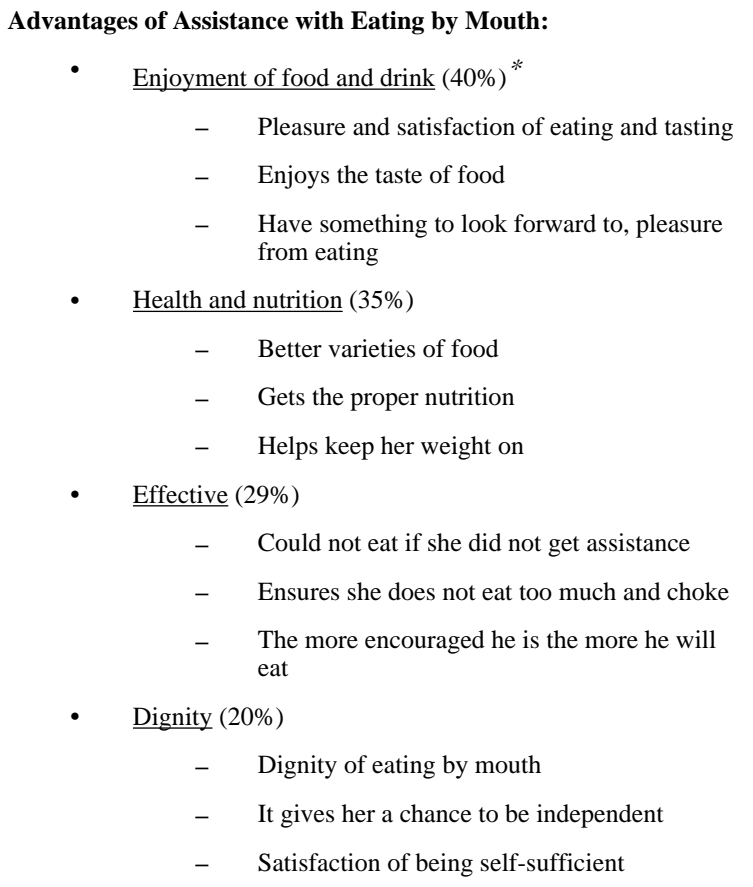 & 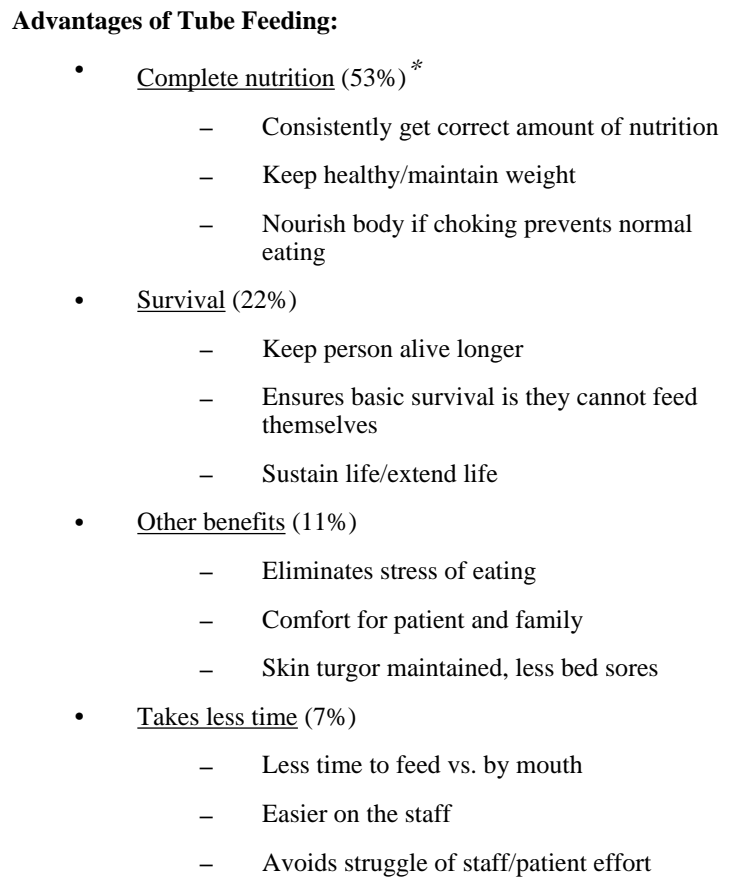 \\
\hline 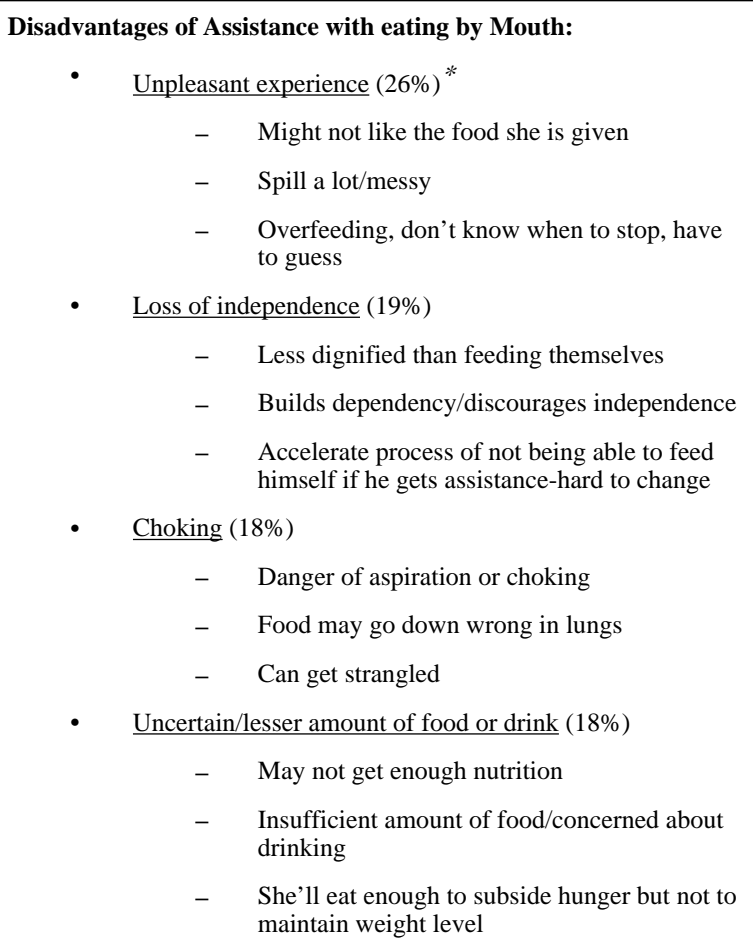 & $\begin{array}{l}\text { isadvantages of Tube Feeding: } \\
\begin{aligned} & \text { Tube-related complications }(38 \%)^{*} \\
&-\quad \text { Infections are possible, need a lot of care to } \\
& \text { keep clean } \\
&- \text { Discomfort, having tube in you } \\
&- \text { Invasive-more risks, complications }\end{aligned} \\
\begin{aligned} & \text { Concern about prolonging life inappropriately }(25 \%) \\
&- \text { Extend life when there is no quality } \\
&- \text { May just prolong the inevitable } \\
&- \text { I believe in natural death, not prolonging life } \\
& \text { - } \text { normally to a place he can't digest his food } \\
& \text { Less enjoyment or pleasure (22\%) } \text { Lose psychological pleasure of eating } \\
&- \text { No quality of life } \\
&- \text { Mental anguish for person-cannot eat by } \\
& \text { - } \text { mouth, always thinking about food }\end{aligned} \\
\begin{aligned} & \text { Against prior wishes (14\%) } \\
&-\quad \text { It would go against his personal wishes } \\
&- \text { Requested that she not be tube fed } \\
&- \text { Person might not want it, against religion }\end{aligned}\end{array}$ \\
\hline
\end{tabular}

percent of surrogates whose response fell within this category 
TABLE 3

Surrogate Knowledge and Treatment Preferences Before and After the Decision Aid

\begin{tabular}{|l|c|c|c|c|}
\hline Interview Measure & $\mathbf{N}$ & Before DA & After DA & p Value \\
\hline Knowledge Score (0-19) & 126 & 15.5 & 16.8 & $<0.001$ \\
\hline Expectation of Benefits index (1-4) & 126 & 2.73 & 2.32 & 0.001 \\
\hline Decisional Conflict scale (1-5) & & & & \\
Overall & 123 & 2.24 & 1.91 & $<0.001$ \\
Uncertainty & 126 & 2.85 & 2.51 & $<0.001$ \\
Effective decision-making & 123 & 1.74 & 1.69 & 0.108 \\
Factors contributing to uncertainty & 119 & 2.23 & 1.78 & $<0.001$ \\
\hline Treatment Preference & 126 & & & \\
Assistance with eating by mouth & & $96 \%$ & $98 \%$ & \\
Feeding tube & & $2 \%$ & $2 \%$ & \\
Don't know & & $2 \%$ & $0 \%$ & 0.372 \\
\hline Certainty about Treatment Preference & 126 & 1.35 & 1.05 & 0.016 \\
\hline
\end{tabular}

